Original Paper

\title{
Influence of Blade Row Distance on Performance and Flow Condition of Contra-Rotating Small-Sized Axial Fan
}

\author{
Toru Shigemitsu', Junichiro Fukutomi ${ }^{1}$ and Hiroki Shimizu ${ }^{2}$ \\ ${ }^{1}$ Institute of Technology and Science, The University of Tokushima \\ 2-1 Minamijosanjima-cho, Tokushima-city, 770-8506, Japan, t-shige@ me.tokushima-u.ac.jp \\ ${ }^{2}$ Graduate School of Advanced Technology and Science, The University of Tokushima \\ 2-1 Minamijosanjima-cho, Tokushima-city, 770-8506, Japan
}

\begin{abstract}
Small-sized axial fans are used as air coolers for electric equipment. There is a strong demand for higher power of fans according to the increase of quantity of heat from electric devices. Therefore, higher rotational speed design is conducted, although, it causes the deterioration of the efficiency and the increase of noise. Then, the adoption of contrarotating rotors for small-sized fans is proposed for the improvement of the performance. In the case of contra-rotating rotors, blade row distance between the front and the rear rotors influences on the performance and the noise. Therefore, it is important to clarify the optimum blade row distance between front and rear rotors. The performance curves of the contra-rotating small-sized axial fan under the condition of different blade row distances are shown and the blade row interaction between the front and the rear rotors are discussed by the numerical results. Furthermore, the optimum blade row distance of the contra-rotating small-sized axial fan is considered.
\end{abstract}

Keywords: Small-sized axial fan, Contra-rotating rotors, Performance, Internal flow, Blade row distance

\section{Introduction}

Because of spread of cloud computing, establishment of ubiquitous networking society and the increase in the rate of electric parts in machines, power consumption in data centers, IT devices and machines has been increasing significantly. In the view of the issue of global warming and energy savings, there is a strong demand for the reduction of power consumption in above facilities and equipment[1]. Electrical power used for the cooling of the IT devices for data centers is huge the same as that used for the IT devices itself in data centers. Small-sized axial fans are used as air coolers for electric equipment i.e. laptop, desk top computers and servers. There is a strong demand for higher power of fans according to the increase of quantity of heat from electric devices. However, the increase of the power by the increase of the fan diameter is restricted because of the limitation of the space. Therefore, higher rotational speed design is conducted, although, it causes the deterioration of the efficiency and the increase of noise. On the other hand, lower rotational speed design[2] and advantages on the performance of the contra-rotating fans and pumps are verified by experimental results[3],[4]. Then, the adoption of contra-rotating rotors for small-sized fans is proposed for the improvement of the performance. In the case of contra-rotating rotors, the axial space becomes larger than conventional small-sized axial fans. However, it is adequate choice to apply the contra-rotating rotors for small sized-fans because the axial space can be ensured in electrical devices as compared to that of the radial space.

In the case of contra-rotating rotors, it is necessary to design rear rotor considering the unsteady circumferential velocity distributions at the outlet of the front rotor[5]. Further, it is important to clarify the influence of the wake from the front rotor to the rear rotor on the performance and pressure interaction between front and rear rotors[6]. On the other hand, the conventional design method and the theory for the turbo machinery should be modified for small-sized axial fans because small-sized axial fans applied to electrical devices belong to extremely small size field in the turbo machinery[7]. Therefore, there is the strong demand to establish the design method for small-sized axial fans. In the case of contra-rotating rotors, blade row distance between the front and the rear rotors influences on the performance and the noise. Therefore, it is important to clarify the optimum blade row distance between front and rear rotors.

In the present paper, the performance curves of the contra-rotating small-sized axial fan with 100mm diameter under the condition of different blade row distances are shown and the internal flow conditions between the front and the rear rotors are clarified by experimental results. Furthermore, the blade row interaction between the front and the rear rotors are discussed by the numerical results and the optimum blade row distance of the contra-rotating small-sized axial fan is considered.

Received June 13 2012; accepted for publication August 20 2012: Review conducted by Prof. Yutaka Ohta. (Paper number O12015J) Corresponding author: Toru Shigemitsu, Associate Professor, t-shige@me.tokushima-u.ac.jp 


\section{Experimental Apparatus and Methods}

The rotor and the primary dimensions of a contra-rotating axial fan(RRtype) are shown in Fig. 1 and Table 1 respectively. The hub tip ratio $D_{\mathrm{h}} / D_{\mathrm{t}}=45 \mathrm{~mm} / 98 \mathrm{~mm}$ and the designed flow rate was $Q_{\mathrm{d}}=0.016 \mathrm{~m}^{3} / \mathrm{s}$ and fan static pressure at the design point was $\Delta P_{\mathrm{dRR}}=14.7 \mathrm{~Pa}$ for RRtype with the same fan static pressure of each front and rear rotor. The rotational speed of front and rear rotors of RRtype was $N_{f}=N_{r}=1780 \mathrm{~min}^{-1}$. In this research, an aerofoil blade was used because there was a report which implied an advantage of the aerofoil blade for the small-sized axial fan[8], however a circular-arc blade was generally used for small-sized axial fans. RRtype rotor used for the experiment was changed a little from the rotor for the numerical analysis in the blade thickness, because the thickness for the numerical analysis rotor was thin and the lack of the strength for using it for the experiment was worried. The minimum thickness of the rotor used for the experiment was set as $2 \mathrm{~mm}$, although, that for the numerical analysis was $1.4 \mathrm{~mm}$. The blade profile of experiment were different from that of numerical analysis due to the variation of the blade thickness between the experimental and numerical analysis models as could be confirmed in Table 1. Both of the rotors used for the experiment and the numerical analysis were designed to achieve the same performance at design condition with the assumption that the efficiency of both front and rear rotors were the same and the circumferential velocity from the front rotor was recovered as static pressure by the rear rotor in both rotors used for the experiment and numerical analysis. The influence of the difference of the rotor between the experiment and the numerical analysis on flow conditions could be small because the thickness of the rotor was mainly changed. Figure 2 shows the schematic diagram of the experimental apparatus for RRtype. The experimental apparatus was designed based on the Japanese Industrial Standard and the air blown in the test section passed the rotor, chamber, measurement duct and booster fan and blew out in the ambient atmosphere. The fan static pressure $(\Delta P)$ was measured by the pressure difference between static holes downstream of the rotor installed at the chamber and ambient air. Fan static pressure of each front and rear rotor was also measured to investigate pressure curves of each front and rear rotor in wide flow rates range. Further, the rotational speed was controlled by the servo motor and the flow rates were measured by the orifice meter set at the measurement duct. The pressure curves from the cutoff flow rate to the large flow rate were investigated in the experiment with the constant rotational speed $N_{\mathrm{f}}=N_{\mathrm{r}}=1780 \mathrm{~min}^{-1}$ for RRtype. The internal flow measurements at the inlet of the front rotor, between front and rear rotors and the outlet of the rear rotor were conducted with a one-hole cylindrical pitot tube having an outer diameter of $2.0 \mathrm{~mm}$. This tube was used as the substitution of a three-hole pitot tube by rotating it by $\pm 30^{\circ}$. The measurements in radial direction were conducted from $r=28.5 \mathrm{~mm}$ to $r=49.5 \mathrm{~mm}$ by interval of $3 \mathrm{~mm}$ at 8 radial positions. Further, the blade row distance was adjusted by installation of the cylindrical hub and alteration of the casing length.

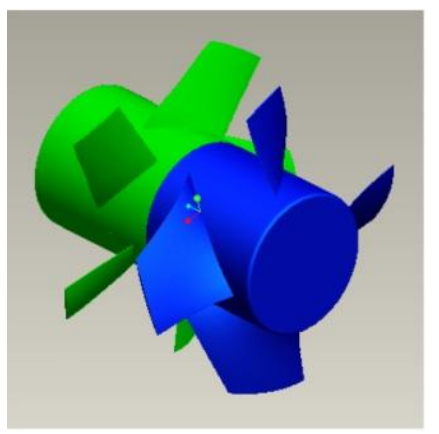

Fig. 1 Contra-rotating small-sized axial fan

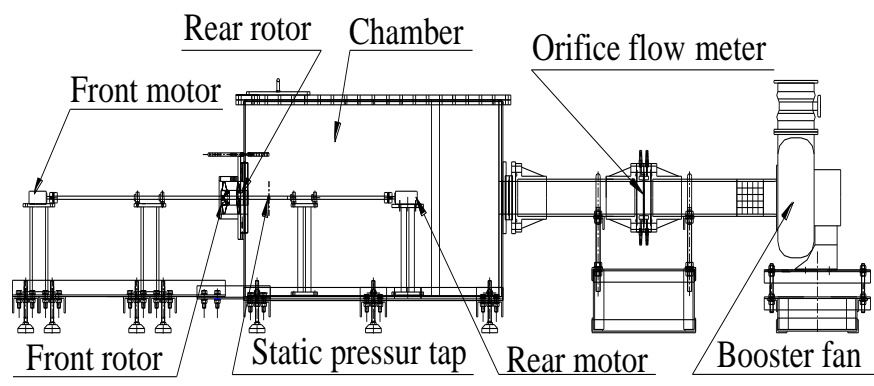

Fig. 2 Experimental apparatus

Table 1 Primary dimensions of RRtypes

\begin{tabular}{|c|c|c|c|c|}
\hline & & Hub & Mid & Tip \\
\hline & Diameter[mm] & 45 & 72 & 98 \\
\hline \multirow{4}{*}{$\begin{array}{l}\text { Front Rotor } \\
\text { (RRtype-exp.) }\end{array}$} & Blade Number & \multicolumn{3}{|c|}{4} \\
\hline & Blade Profile & \multicolumn{3}{|c|}{ NACA 4409} \\
\hline & Solidity & 1.196 & 0.496 & 0.29 \\
\hline & Stagger Angle & $44.67^{\circ}$ & $61.09^{\circ}$ & $68.15^{\circ}$ \\
\hline \multirow{4}{*}{$\begin{array}{c}\text { Rear Rotor } \\
\text { (RRtype-exp.) }\end{array}$} & Blade Number & \multicolumn{3}{|c|}{5} \\
\hline & Blade Profile & \multicolumn{3}{|c|}{ NACA 4412} \\
\hline & Solidity & 0.91 & 0.447 & 0.288 \\
\hline & Stagger Angle & $56.73^{\circ}$ & $64.54^{\circ}$ & $69.60^{\circ}$ \\
\hline \multirow{4}{*}{$\begin{array}{l}\text { Front Rotor } \\
\text { (RRtype-cal.) }\end{array}$} & Blade Number & \multicolumn{3}{|c|}{4} \\
\hline & Blade Profile & \multicolumn{3}{|c|}{ NACA 4406} \\
\hline & Solidity & 1.245 & 0.508 & 0.308 \\
\hline & Stagger Angle & $42.40^{\circ}$ & $60.11^{\circ}$ & $67.21^{\circ}$ \\
\hline \multirow{4}{*}{$\begin{array}{l}\text { Rear Rotor } \\
\text { (RRtype-cal.) }\end{array}$} & Blade Number & \multicolumn{3}{|c|}{5} \\
\hline & Blade Profile & \multicolumn{3}{|c|}{ NACA 4409} \\
\hline & Solidity & 0.91 & 0.447 & 0.288 \\
\hline & Stagger Angle & $55.92^{\circ}$ & $63.91^{\circ}$ & $68.87^{\circ}$ \\
\hline
\end{tabular}




\section{Numerical Analysis Conditions}

The commercial software ANSYS-Fluent was used to investigate the flow condition which couldn't be measured by the experiment. In the numerical analysis, the numerical model which was almost the same with the experimental apparatus was used and three dimensional unsteady numerical analysis was conducted. The numerical grids used for the numerical analysis are shown in Fig.3. In order to keep the numerical analysis domains the same with the experimental apparatus, the numerical domains comprised the inlet, the rotor, the chamber and the outlet duct regions, however the computational cost would increase. The numerical grid numbers were 218,039 for the inlet region, 667,135 for the chamber region and 39,875 for the outlet duct region. The numerical grid numbers for the rotor regions were $3,613,381$. The number of nodes along the front and the rear rotor blades at the hub were 150 nodes and 80 nodes. The number of nodes of blade-to-blade of the front and the rear rotors were 35 nodes and 30 nodes. The number of nodes from hub to tip of the front and the rear rotors were 110 nodes and 100 nodes. The tip clearance was kept $1 \mathrm{~mm}$ as the same with the experimental apparatus in the numerical analysis and the number of nodes from the blade tip to the casing was 7 nodes. The numerical grids over 150,000 were ensured at the tip clearance. The $\mathrm{y}^{+}$was 15 near the hub of the rotor. At the inlet boundary, the uniform velocity was given and the constant pressure was given as the outlet boundary condition. Each front and rear rotor was defined to rotate in the opposite direction in the numerical analysis and the coupling between the stationary region and the rotating region and between the front and the rear rotors was accomplished by the sliding mesh. The standard wall function and SST $k$ - $\omega$ turbulence model was used. The unsteady numerical flow analysis was conducted at the designed flow rate. The time step number per one rotor rotation was 200 and the time step was $t=1.6854 \times 10^{4} \mathrm{~s}$. The data of one rotor rotation were obtained after 6 rotor rotations in unsteady numerical analysis. The convergence criteria at each time step were set as $1.0 \times 10^{-4}$.

\section{Results and discussions}

Fan static pressures of each blade row distance are shown in Fig.4. The non-dimensional blade row distance divided by the blade chord length of the front rotor at tip were $L / l_{\mathrm{FR}}=0.422(L=10 \mathrm{~mm}), L / l_{\mathrm{FR}}=1.27(L=30 \mathrm{~mm}), L / l_{\mathrm{FR}}=2.11(L=50 \mathrm{~mm})$ and $L_{\mathrm{FR}} / l=4.22(L=100 \mathrm{~mm})$. The fan static pressure kept almost constant by the blade row distance between the front and rear rotors was $L=30 \mathrm{~mm}$. The difference of the static pressure between $L=10 \mathrm{~mm}$ and $L=30 \mathrm{~mm}$ at the designed flow rate $Q_{\mathrm{d}}=0.016 \mathrm{~m}^{3} / \mathrm{s}$ was $\triangle P=0.02 \mathrm{~Pa}$. Although, the fan static pressure deteriorated over the blade row distance $L=30 \mathrm{~mm}$. The fan static pressure of $L=50 \mathrm{~mm}$ and $L=100 \mathrm{~mm}$ decreased by $\Delta P=0.42 \mathrm{~Pa}$ and $\Delta P=0.77 \mathrm{~Pa}$ from that of $L=30 \mathrm{~mm}$ respectively. On the other hand, the decrease of the fan static pressure according to the increase of the blade row distance at partial flow rate was larger than that at designed flow rate. It was found that the influence of the blade row distance at the partial flow rate was larger than that at the

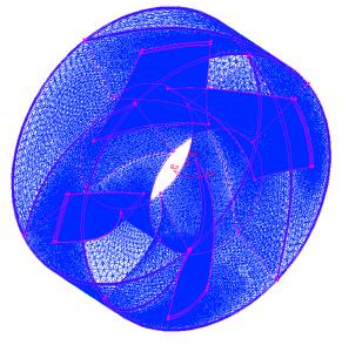

(a) Front rotor

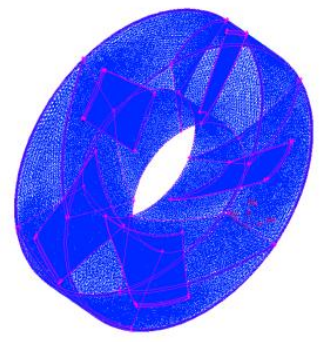

(b) Rear rotor

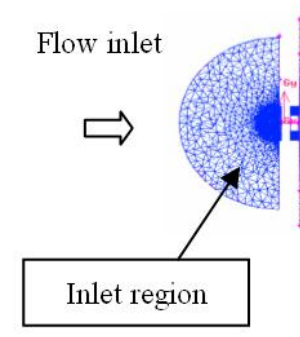

(c) Whole domains

Fig. 3 Numerical analysis grids

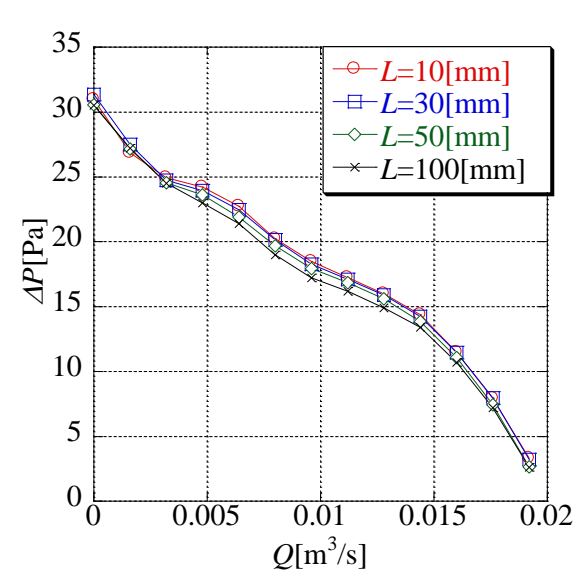

Fig. 4 Fan static pressure curves

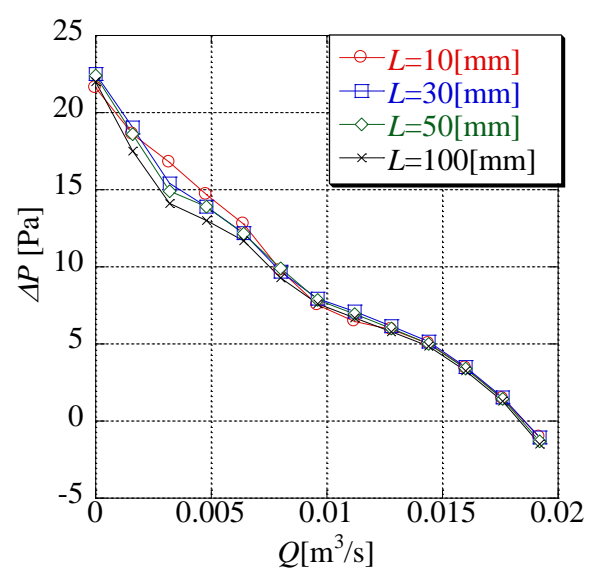

(a) Front rotor

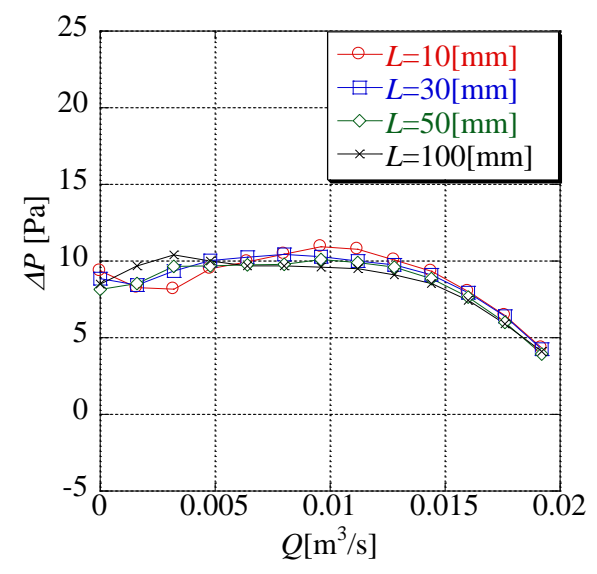

(b) Rear rotor

Fig. 5 Fan static pressure curves of front and rear rotors 
designed flow rate. Fan static pressures of the front and the rear rotors for different blade row distances are shown in Figs.5(a) and (b) respectively. The fan static pressure of the front rotor was almost constant in all case with the different blade row distances. On the other hand, the fan static pressure of the rear rotor kept constant by the blade row distance $L=30 \mathrm{~mm}$ and decreased gradually over the blade row distance $L=30 \mathrm{~mm}$. It was known that the blade row distance influenced on the performance of the rear rotor. Therefore, the internal flow conditions at the inlet of the front rotor, between the front and the rear rotors and the outlet of the rear rotor for the different blade row distance were investigated experimentally.

Figures 6(a) and (b) show the axial velocity and circumferential velocity distributions at the inlet of the front rotor of each blade row distance in radial direction obtained by the experiment at the designed flow rate $Q_{\mathrm{d}}=0.016 \mathrm{~m}^{3} / \mathrm{s}$. The measuring position in axial direction was $5 \mathrm{~mm}$ upstream of the front rotor leading edge at the hub. The vertical axis is non-dimensional radius divided by the radius at the casing; $r / r_{\mathrm{c}}=0.45$ and $r / r_{\mathrm{c}}=1.0$ correspond the hub and the casing. Further, the circumferential velocity $V_{\mathrm{t}}$ is a positive in the direction of the front rotor rotation. The axial velocities of all cases with different blade row distance showed the uniform value which were almost the same with designed axial velocity as $V_{\mathrm{z}}=2.554 \mathrm{~m} / \mathrm{s}$. On the other hand, the circumferential velocities were almost zero in all cases with different blade row distance and air came in without the swirl flow at the inlet of the front rotor. Therefore, the flow conditions at the inlet of the front rotor were stable and uniform in radial direction regardless of the change of the blade row distance between the front and the rear rotors.

Figures 7(a) and (b) show the axial velocity and the circumferential velocity distributions between the front and the rear rotors of each blade row distance in radial direction obtained by the experiment at the designed flow rate $Q_{\mathrm{d}}=0.016 \mathrm{~m}^{3} / \mathrm{s}$. The measurement positions in axial direction for each blade row distance were $5 \mathrm{~mm}$ upstream of the leading edge of the rear rotor hub respectively regardless of the difference of the blade row distance. The vertical axis is the same with Figs.6. The axial velocity decreased near tip region $r / r_{\mathrm{c}}>0.7$ between the front and the rear rotors. On the contrary, the axial velocity increased near the hub by the influence of the decrease of the axial velocity near the tip. The tendencies of the axial velocity distributions for each blade row distance were similar to each other. On the other hand, the circumferential velocity near the tip region was almost the same value with that near the hub region because of the decrease of the axial velocity near the tip region in Fig.7(a), although, the free vortex design $\left(r V_{\mathrm{t}}=\mathrm{const}\right)$ was applied in the rotor design. Further, the circumferential velocity decreased gradually according to the increase of the blade row distance near the tip region. It was considered that the decrease of the circumferential velocity was mainly caused by the frictional loss near the casing wall. Then, in order to evaluate the influence of the circumferential velocity decrease on pressure decrease, flow rate weighed dynamic pressure of circumferential velocity component evaluated by the velocity distribution in radial direction was calculated. The flow rate weighed average dynamic pressure of the circumferential velocity component $5 \mathrm{~mm}$ upstream of the rear rotor was $P_{\mathrm{d}}=1.9 \mathrm{~Pa}$ for blade rows distance $L=10 \mathrm{~mm}$ and that for the blade rows

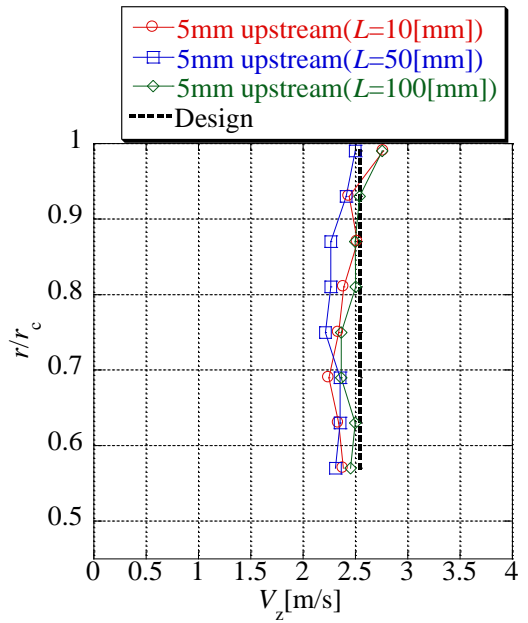

(a) Axial velocity distributions

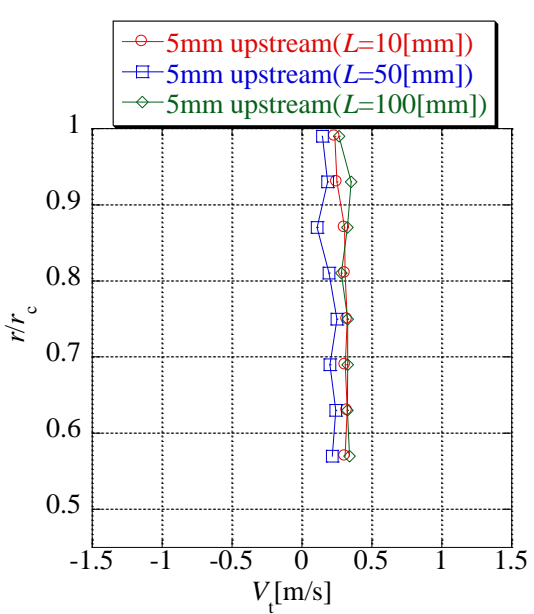

(b) Circumferential velocity distributions

Fig. 6 Velocity distributions at the inlet of the front rotor $\left(Q_{\mathrm{d}}=0.016 \mathrm{~m}^{3} / \mathrm{s}\right)$

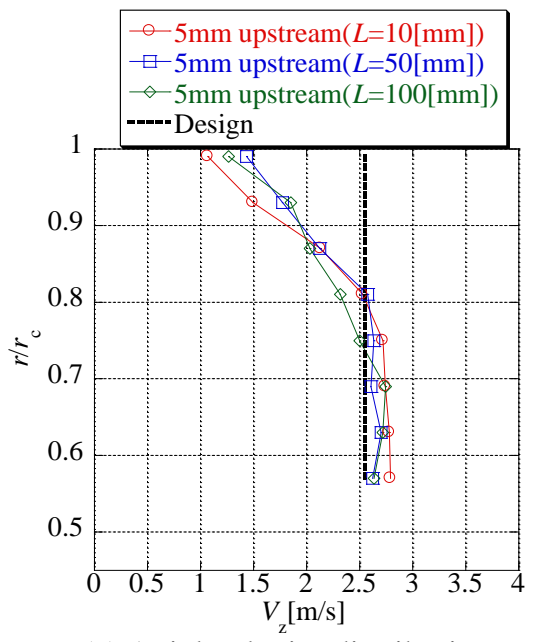

(a) Axial velocity distributions

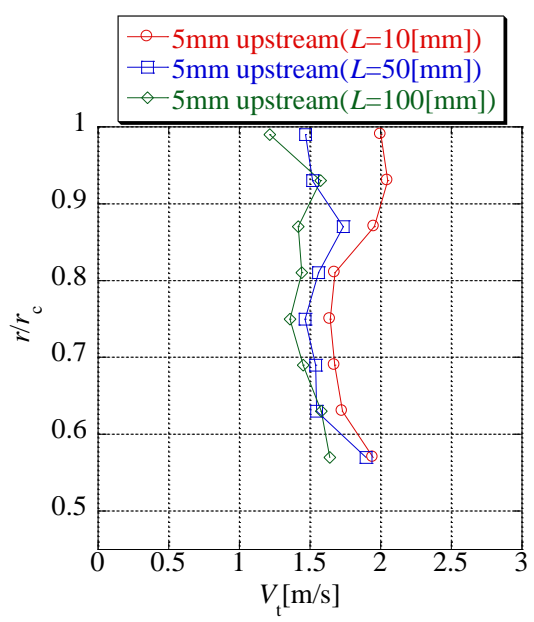

(b) Circumferential velocity distributions

Fig. 7 Velocity distributions between front and rear rotors $\left(Q_{\mathrm{d}}=0.016 \mathrm{~m}^{3} / \mathrm{s}\right)$ 
distance $L=100 \mathrm{~mm}$ was $P_{\mathrm{d}}=1.3 \mathrm{~Pa}$. The difference of the dynamic pressure of the circumferential velocity component between $L=10 \mathrm{~mm}$ and $L=100 \mathrm{~mm}$ was $\Delta P_{\mathrm{d}}=0.6 \mathrm{~Pa}$. If the all dynamic pressure decrease $0.6 \mathrm{~Pa}$ for the case with $L=100 \mathrm{~mm}$ could become the loss, the rate of the dynamic pressure loss $(0.6 \mathrm{~Pa})$ against the difference of the fan static pressure between $L=10 \mathrm{~mm}$ and $L=100 \mathrm{~mm}(0.77 \mathrm{~Pa})$ in Fig.4 was about $78 \%$. Therefore, the circumferential velocity decrease between the front and the rear rotors; frictional loss, could be the main reason of the fan static pressure decrease of $L=100 \mathrm{~mm}$. It was considered that it was difficult to convert the circumferential velocity of $L=100 \mathrm{~mm}$ at the front rotor outlet to the static pressure between the front and the rear rotors. Eventually, it could be concluded that the fans static pressure decreased mainly by the frictional loss between the front and the rear rotors in the case of the contra-rotating small-axial fan and the large increase of the blade rows distance between the front and the rear rotors should be avoided.

Figures 8(a) and (b) show the axial velocity and circumferential velocity distributions at the outlet of the rear rotor in radial direction obtained by the experiment at the designed flow rate $Q_{\mathrm{d}}=0.016 \mathrm{~m}^{3} / \mathrm{s}$. The measurement positions in axial direction for each blade row distance were $6 \mathrm{~mm}$ downstream of the trailing edge of the rear rotor hub respectively. The vertical axis is the same with Figs.6. The axial velocities were small near the tip in all case of the different blade row distances. It was considered that this would be caused by small radius of the inlet bell mouse, the leakage flow from the blade tip and boundary layer near the casing. Further, there were no large differences of axial velocity in all cases of the blade row distances. On the other hand, focused on the circumferential velocity distributions, the circumference velocities at the outlet of the rotor were almost zero in all cases of the different blade row distances, however, there were small differences between the cases of $L=10 \mathrm{~mm}$ and $L=100 \mathrm{~mm}$.

The flow rate weighed average total pressure distributions at designed flow rate $Q_{\mathrm{d}}=0.016 \mathrm{~m}^{3} / \mathrm{s}$ in axial direction for each blade row distance are shown in Fig.9. The horizontal axis of Fig.9 shows the axial distance from the leading edge of the front rotor at the hub. It was also confirmed from Fig.9 that the total pressure between the front and the rear rotors decreased according to the increase of the blade row distance. It was also found from these results that the circumferential velocity at the outlet of the front rotor could become the loss between the front and the rear rotors.

Pressure distribution of the rear rotor influences on pressure distribution of the front rotor in the case with the small blade row distance. Therefore, the pressure interaction between the front and the rear rotors was investigated by the numerical analysis in the case of the small blade row distance $L=10 \mathrm{~mm}$ and $30 \mathrm{~mm}$. Figures 10 and 11 show the static pressure distribution of $L=10 \mathrm{~mm}$ and $L=30 \mathrm{~mm}$ at $r / r_{\mathrm{c}}=0.75$ respectively. $\theta_{\mathrm{f}}$ and $\theta_{\mathrm{r}}$ represent rotation angles of each front and rear rotor leading edge from the meridional plane. $\theta_{\mathrm{f}}=0 \mathrm{deg}$ and $\theta_{\mathrm{r}}=0 \mathrm{deg}$ correspond the circumferential position that the leading edge of each front and rear rotor accord the meridional plane. The relative circumferential position of each front and rear rotor is that the rear rotor rotation angle is $\theta_{\mathrm{r}}=-18 \mathrm{deg}$

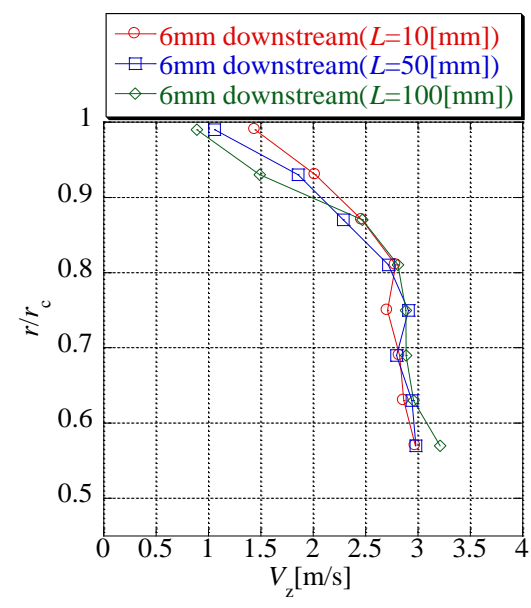

(a) Axial velocity distributions

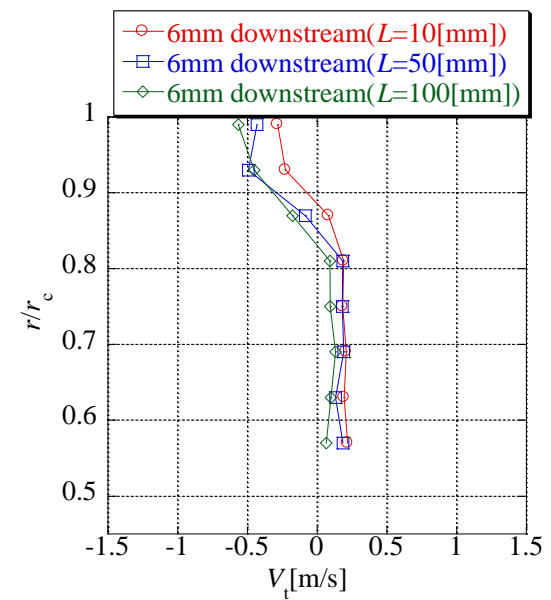

(b) Circumferential velocity distributions

Fig. 8 Velocity distributions at the outlet of the rear rotor $\left(Q_{\mathrm{d}}=0.016 \mathrm{~m}^{3} / \mathrm{s}\right)$

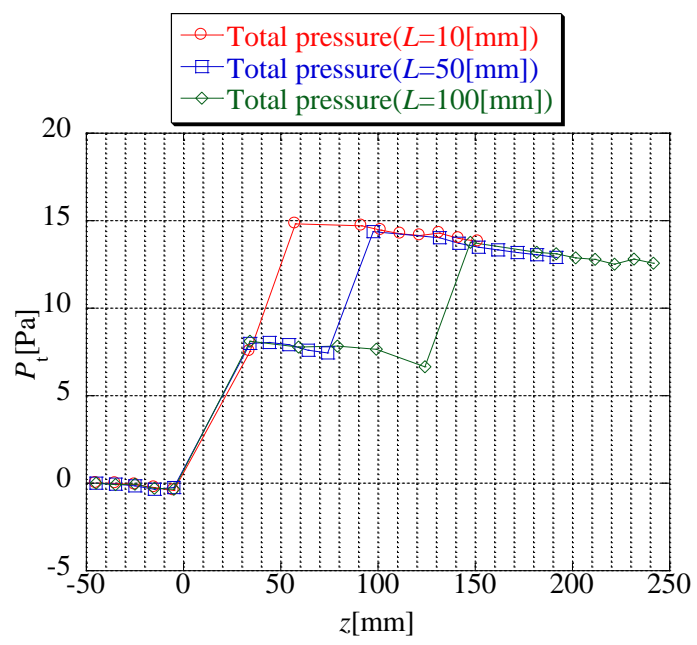

Fig. 9 Axial distributions of total pressure increase $\left(Q_{\mathrm{d}}=0.016 \mathrm{~m}^{3} / \mathrm{s}\right)$ 
when the front rotor rotation angle is $\theta_{\mathrm{f}}=0 \mathrm{deg}$. The static pressure distribution on the suction surface of the rear rotor influenced on that on the pressure surface of the front rotor for the case of $L=10 \mathrm{~mm}$ at $\theta_{\mathrm{f}}=21.6 \mathrm{deg}, \theta_{\mathrm{r}}=3.6 \mathrm{deg}$ and $\theta_{\mathrm{f}}=28.8 \mathrm{deg}, \theta_{\mathrm{r}}=10.8 \mathrm{deg}$ in Figs.10(c),(d). On the other hand, the static pressure distribution didn't reach the pressure distribution of the front rotor in the case for $L=30 \mathrm{~mm}$ in Figs 11. Further, the noise due to the interaction between the front and the rear rotors could be large in the case of $L=10 \mathrm{~mm}$ from the results of the pressure distribution in Fig.10. It was considered that the pressure interaction in the case of $L=30 \mathrm{~mm}$ was small and the $L=30 \mathrm{~mm}$ was an appropriate blade row distance for the contra-rotating small-sized axial fan of $100 \mathrm{~mm}$ diameter with this specification from these results. The fan static pressure kept constant by the blade row distance $L=30 \mathrm{~mm}$. Therefore, the blade row distance $L=30 \mathrm{~mm}$ was suitable on the point of view of the performance.

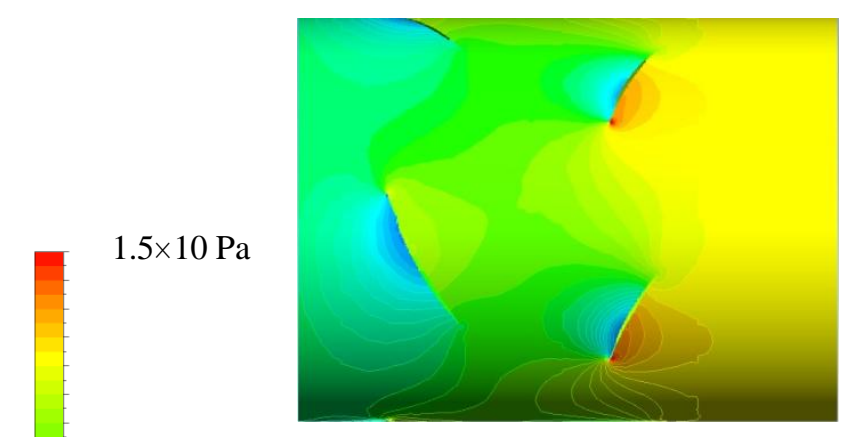

(a) $\theta_{\mathrm{r}}=7.2^{\circ}, \theta_{\mathrm{r}}=-10.8^{\circ}$

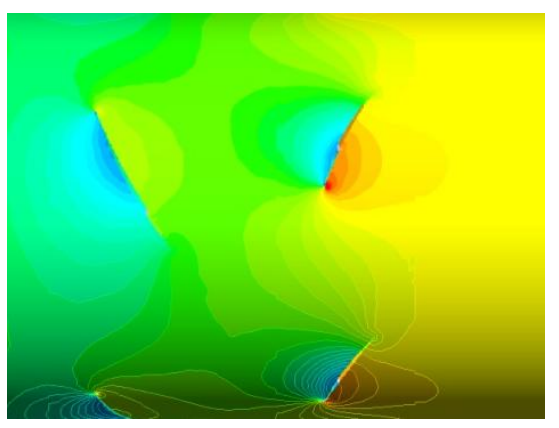

(c) $\theta_{\mathrm{r}}=21.6^{\circ}, \theta_{\mathrm{r}}=3.6^{\circ}$

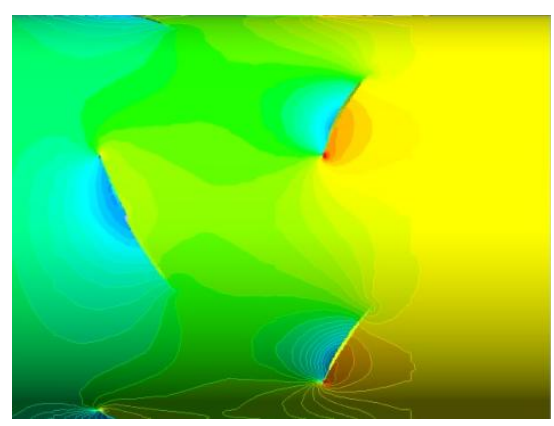

(b) $\theta_{\mathrm{r}}=14.4^{\circ}, \theta_{\mathrm{r}}=-3.6^{\circ}$

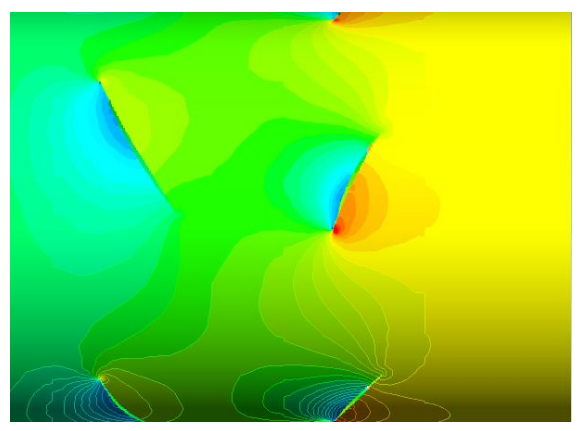

(d) $\theta_{\mathrm{r}}=28.8^{\circ}, \theta_{\mathrm{r}}=10.8^{\circ}$

Fig. 10 Static pressure distribution $\left(Q_{\mathrm{d}}=0.016 \mathrm{~m}^{3} / \mathrm{s}, L=10 \mathrm{~mm}, r / r_{\mathrm{c}}=0.75\right)$

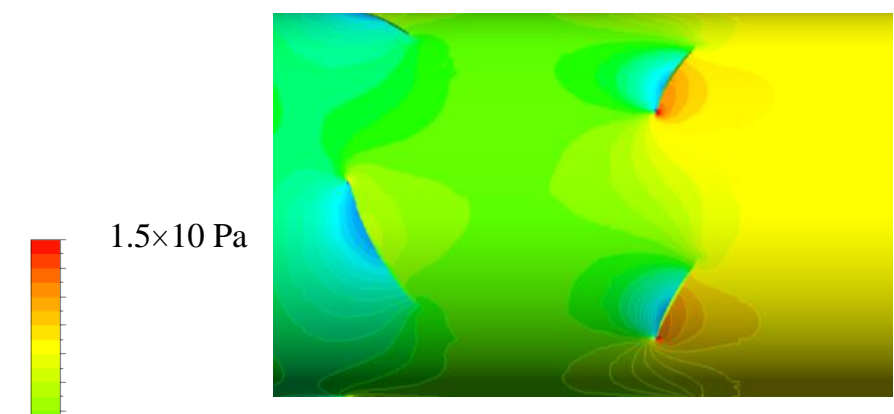

(a) $\theta_{\mathrm{r}}=7.2^{\circ}, \theta_{\mathrm{r}}=-10.8^{\circ}$

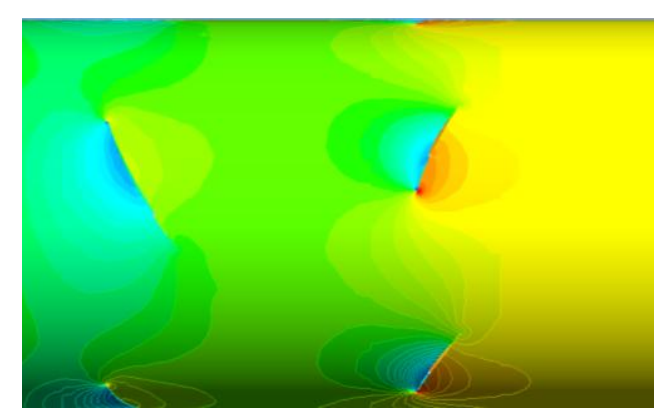

(c) $\theta_{\mathrm{r}}=21.6^{\circ}, \theta_{\mathrm{r}}=3.6^{\circ}$

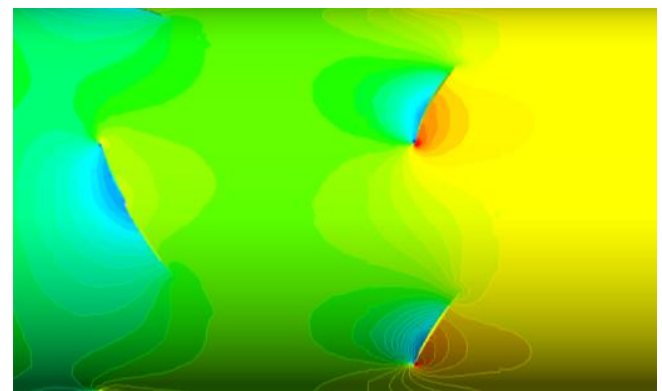

(b) $\theta_{\mathrm{r}}=14.4^{\circ}, \theta_{\mathrm{r}}=-3.6^{\circ}$

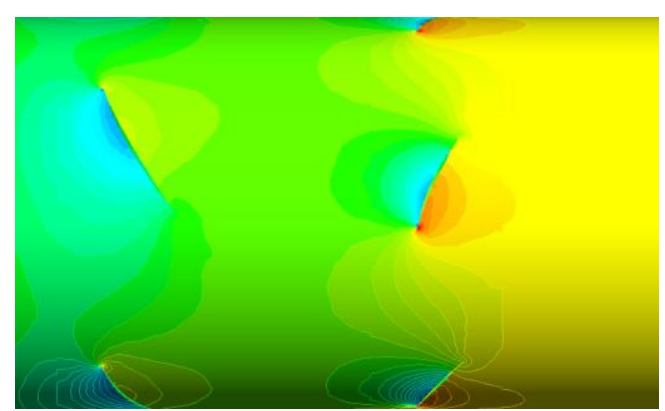

(d) $\theta_{\mathrm{r}}=28.8^{\circ}, \theta_{\mathrm{r}}=10.8^{\circ}$

Fig. 11 Static pressure distribution $\left(Q_{\mathrm{d}}=0.016 \mathrm{~m}^{3} / \mathrm{s}, L=30 \mathrm{~mm}, r / r_{\mathrm{c}}=0.75\right)$ 


\section{Conclusion}

The performance and the internal flow conditions between front and rear rotors of the contra-rotating small-sized axial fan were investigated by the experiment and the numerical analysis. As a result, following concluding remarks were obtained.

1. The fan static pressure of the contra-rotating small sized axial fan kept almost constant by the blade row distance $L=30 \mathrm{~mm}\left(L / l_{\mathrm{FR}}=1.27\right)$.

2. The circumferential velocity between the front and the rear rotors decreased with the increase of the blade row distance by the frictional loss of the casing wall.

3. Blade row distance between the front and the rear rotors $L=30 \mathrm{~mm}\left(L / l_{\mathrm{FR}}=1.27\right)$ was an appropriate blade row distance on the point of view of the performance and the pressure interaction.

\section{Acknowledgments}

The authors wish to show our special thanks to the supports by the Komiya research aid, the project research aid from The University of Tokushima and Japan Science and Technology Agency.

\section{Nomenclature}

\begin{tabular}{|c|c|c|c|}
\hline$D_{\mathrm{h}}$ & Hub diameter $[\mathrm{m}]$ & $\Delta P_{\mathrm{d}}$ & Designed fan static pressure $[\mathrm{Pa}]$ \\
\hline$D_{\mathrm{t}}$ & Tip diameter $[\mathrm{m}]$ & $Q$ & Flow rate $\left[\mathrm{m}^{3} / \mathrm{s}\right]$ \\
\hline$l_{F R}$ & Blade chord length of front rotor at the tip & $Q_{\mathrm{d}}$ & Designed flow rate $\left[\mathrm{m}^{3} / \mathrm{s}\right]$ \\
\hline$L$ & Blade row distance between the front and the rear & $r$ & Radius $[\mathrm{m}]$ \\
\hline & rotors $[\mathrm{mm}]$ & $r_{\mathrm{c}}$ & Radius at the casing $[\mathrm{m}]$ \\
\hline$N_{\mathrm{f}}$ & Rotational speed of the front rotor $\left[\mathrm{min}^{-1}\right]$ & $V_{\mathrm{t}}$ & Circumferential component of absolute velocity \\
\hline$N_{\mathrm{r}}$ & Rotational speed of the rear rotor $\left[\mathrm{min}^{-1}\right]$ & & {$[\mathrm{m} / \mathrm{s}]$} \\
\hline$P_{\mathrm{d}}$ & Dynamic pressure $[\mathrm{Pa}]$ & $V_{\mathrm{z}}$ & Axial component of absolute velocity $[\mathrm{m} / \mathrm{s}]$ \\
\hline$P_{\mathrm{t}}$ & Total pressure $[\mathrm{Pa}]$ & $Z$ & Axial distance $[\mathrm{m}]$ \\
\hline
\end{tabular}

\section{References}

[1] Miyahara, M and Fukano, T., 2006, "Fan Cooling Technology for Small Electronic Device,” Turbomachinery(in Japanese), Vol. 34, No. 3, pp. 129-134.

[2] Furukawa, A., Shigemitsu, T and Watanabe, S., 2007, "Performance Test and Flow Measurement of Contra-Rotating Axial Flow Pump," J. Thermal Science, Vol. 16, No. 1, pp. 7-13.

[3] Furukawa, A., Cao, Y., Okuma, K and Watanabe, S., 2000, "Experimental Study of Pump Characteristics of Contra-Rotating Axial Flow Pump," Proc. $2^{\text {nd }}$ Int. Symp. on Fluid Machinery and Fluid Eng., Beijing, 67-657, pp. 245-252.

[4] Kodama, Y., Hayashi, H., Fukano, T and Tanaka, K., 1994, "Experimental Study on the Characteristics of Fluid Dynamics and noise of a Counter-Rotating Fan $\left(1^{\text {st }}\right.$ Report, Effects of the Supporter Shape of the Electric Motor and the Distance between Two Rotors on the Characteristics)," Trans. JSME (in Japanese), Vol. 60, No. 576, pp. 2764-2771.

[5] Shigemitsu, T., Furukawa, A., Okuma, K and Watanabe, S., 2002, "Experimental Study on Rear Rotor Design in ContraRotating Axial Flow Pump," Proc. 5th JSME/KSME Fluids Eng. Conf., Nagoya, (2002), pp. 1453-1548.

[6] Sanders, A, J., Papalia, J and Fleeter, S., 2002, "Multi-Blade Row Interactions in a Transonic Axial Compressor: Part I- Stator Particle Image Velocimetry (PIV) Investigation,” ASME J. Turbomachinery, Vol. 124, No. 1, pp. 10-18.

[7] Shigemitsu, T., Fukutomi, J and Okabe, Y., 2010, "Performance and Flow Condition of Small-Sized Axial Fan and Adoption of Contra-Rotating Rotors," J. Thermal Science., Vol. 19, No. 1, pp. 1-6.

[8] Ito, T., Minorikawa, G., Nagamatsu, A and Suzuki, S., 2006, "Experimental Research for Performance and Noise of Small Axial Flow Fan(influence of Parameter of Blade)," Trans. JSME (in Japanese), Vol. 72, No. 715, pp. 670-677. 